\title{
RESPONS PERTUMBUHAN AKSESI LADA (Piper nigrum L.) HASIL IRADIASI SINAR GAMMA TERHADAP ZAT PENGATUR TUMBUH ROOTONE F DAN AIR KELAPA
}

\section{GROWTH RESPONSE ON ACCESSIONS OF PEPPER (Piper nigrum L.) FROM GAMMA IRRADIATION TO ROOTONE F AND COCONUT WATER OF PLANT GROWTH REGULATOR}

\author{
Rita Amelia ${ }^{1}$, Nur Laela Wahyuni Meilawati ${ }^{2}$, Siti Nurhidayah ${ }^{1}$ \\ ${ }^{1}$ Program Studi Agroteknologi Fakultas Pertanian Universitas Perjuangan Tasikmalaya, \\ Jalan Pembela Tanah Air No. 177, Kecamatan Tawang, Tasikmalaya, Jawa Barat 46115 \\ ${ }^{2}$ Balai Penelitian Tanaman Rempah dan Obat, Jalan Tentara Pelajar No.3, Cimaggu, Bogor 16111 \\ *Korespondensi : nurlaelawm29@gmail.com
}

\begin{abstract}
ABSTRAK
Lada merupakan komoditas ekspor yang menguntungkan dan kaya manfaat. Hal ini menyebabkan permintaan benih lada yang berasal dari setek batang meningkat. Untuk memenuhi permintaan benih lada dibutuhkan peningkatan keberhasilan hidup setek batang. Salah satu caranya yaitu penggunaan zat pengatur tumbuh (ZPT). Beberapa ZPT akan diujikan pada lima aksesi lada hasil iradiasi sinar gamma. Aksesi ini membutuhkan waktu sekitar tiga minggu untuk menumbuhkan akar atau tunas. Penelitian ini bertujuan untuk mengetahui respons pertumbuhan aksesi lada hasil iradiasi sinar gamma terhadap zat pengatur tumbuh Rootone F dan air kelapa. Penelitian dilaksanakan pada bulan Januari - Juni 2020 di Rumah Kaca Balai Penelitian Tanaman Rempah dan Obat (Balittro), Bogor. Rancangan yang digunakan adalah Rancangan Acak Kelompok dua faktor. Faktor pertama adalah jenis aksesi yang terdiri dari lima jenis yaitu MP1, MP2, MP3, MP4 dan varietas Ciinten. Faktor kedua adalah ZPT yang terdiri dari tujuh taraf yaitu Rootone F 0.5 g, Rootone F 1 g, Rootone F 1.5 g, air kelapa 25\%, air kelapa 50\%, air kelapa 75\% dan tanpa ZPT (kontrol). Hasil penelitian menunjukkan bahwa respons aksesi MP3 dan MP4 memiliki jumlah tunas, tinggi tunas, jumlah daun, panjang daun, dan lebar daun lebih baik daripada varietas Ciinten. Respons perlakuan ZPT Rootone F $0.5 \mathrm{~g}$ memiliki daun lebih lebar dan jumlah daun lebih banyak dibandingkan dengan air kelapa 75\%, namun tidak berbeda nyata dengan kontrol pada umur 7 MST. Terdapat interaksi ZPT dan aksesi yang diuji dimana seluruh kombinasi memiliki persentase hidup $>75 \%$ kecuali perlakuan Rootone F $1.5 \mathrm{~g}$ aksesi MP1 memiliki persentase hidup nyata lebih rendah.
\end{abstract}

Kata kunci: Air kelapa, aksesi, lada, setek, Rootone F

\section{ABSTRACT}

Pepper is a profitable export commodity and rich in benefits. This is causing the increased demand for pepper seeds derived from stem cutting. To meet the demand for pepper seeds, it is necessary to increase the survival rate of stem cuttings. One of the methods used is the use of growth regulators (ZPT). Some ZPT will be tested on five pepper accessions resulting from gamma-ray irradiation. This accession takes about three weeks to grow roots or shoots. This study aims to determine the growth responses of accession of gamma-ray irradiated pepper to rootone $\mathrm{F}$ growth regulators and coconut water. The research was conducted in January - June 2020 at the Greenhouse of the Indonesian Spice and Medicinal Crops Plants Research Institute (Balittro), Bogor. The experimental design used is a two-factor Randomized Block Design. The first factor is accession, consisting of five types, namely MP1, MP2, MP3, MP4, and Ciinten varieties. The second factor is ZPT, which consists of seven levels: Rootone F 0.5 g, Rootone F $1 \mathrm{~g}$, Rootone F $1.5 \mathrm{~g}$, coconut water $25 \%$, coconut water $50 \%$, coconut water $75 \%$, and without ZPT (control). The 
results showed that respons of MP3 and MP4 accession has the shoot number, shoot height, number of leaves, leaf length, and leaf width is better than Ciinten varieties. Respons of ZPT Rootone F $0.5 \mathrm{~g}$ has wider leaves and $75 \%$ more leaves than coconut water, but it is no different from the control at 7 MST. There were interactions between ZPT and accessions tested where all combinations had a survival rate> 75\% except for Rootone F treatment $1.5 \mathrm{~g}$ MP1 accessions had a lower real life percentage.

Keywords: accession, coconut water, cuttings, pepper, Rootone F

\section{PENDAHULUAN}

Lada merupakan komoditas yang menguntungkan dan kaya manfaat. Lada termasuk komoditas ekspor urutan ke-6 setelah karet, kopi, kelapa sawit, teh dan tembakau (Zuhroh et al., 2019). Peningkatan jumlah ekspor mengakibatkan meningkat pula permintaan benih lada terutama asal setek batang yang memiliki keunggulan memiliki umur yang sama dengan induknya.

Ketersediaan benih yang berasal dari setek batang terbatas karena keberhasilan hidup setek batang lada yang rendah. Oleh karena itu diperlukan metode untuk meningkatkan keberhasilan setek batang lada. Salah satu cara yang digunakan yaitu penggunaan zat pengatur tumbuh (ZPT). ZPT dapat meningkatkan pertumbuhan tanaman lada serta memenuhi kebutuhan unsur haranya.

Aplikasi ZPT dapat dilakukan menggunakan ZPT sintesis atau alami. Menurut Budianto et al. (2013) auksin (IBA, IAA, NAA) merupakan komponen ZPT yang berfungsi dalam pembentukan jumlah dan panjang akar. Rootone $\mathrm{F}$ merupakan salah satu ZPT sintesis yang mengandung auksin. Salah satu ZPT alami yang dapat meningkatkan pertumbuhan vegetatif adalah air kelapa. Air kelapa mengandung senyawasenyawa biologi aktif yang terdiri dari mineral, vitamin, gula, asam amino dan fitohormon yang memiliki efek sangat signifikan untuk pertumbuhan tanaman (Darlina et al., 2016).

Penggunaan Rootone $\mathrm{F}$ dan air kelapa diharapkan dapat mempengaruhi keberhasilan setek lada yang diuji coba pada lima aksesi tanaman lada hasil iradiasi sinar gamma. Penelitian ini bertujuan untuk mengetahui respons pertumbuhan aksesi lada hasil iradiasi sinar gamma terhadap zat pengatur tumbuh yang Rootone F dan air kelapa.

\section{BAHAN DAN METODE}

\section{Waktu dan Tempat}

Penelitian dilaksanakan pada bulan Januari sampai Juni 2020 di Rumah Kaca Balai Penelitian Tanaman Rempah dan Obat (Balittro), Bogor pada ketinggian 220 - $234 \mathrm{~m} \mathrm{dpl}$. 
Bahan setek batang berasal dari benih lada Varietas Ciinten yang diiradiasi sinar gamma. Berdasarkan penelitian yang dilakukan oleh Meilawati et al. (2016) fase benih yaitu biji lada yang berwarna merah dipisahkan antara kulit dan benihnya, sedangkan fase benih dengan radikula yaitu benih lada yang sudah terpisah dari kulitnya diletakkan pada cawan petri kemudian diseleksi pada hari ke 12-15, untuk mendapatkan radikula lada dengan ukuran sekitar 0,1$1 \mathrm{~cm}$, kemudian keduanya diberi perlakuan iradiasi sinar gamma dengan tujuh taraf yaitu $(0,25,50,75,100,125$, 150) Gy di Pair Batan.

\section{Bahan dan Alat}

Bahan yang digunakan adalah tanah, arang sekam, pupuk kandang, benih setek lada, Rootone F, air kelapa, air mineral. Alat yang digunakan adalah polibag, gelas air mineral, cutter, alat tulis, gelas ukur, timbangan, plastik, kertas koran, karet gelang dan alat pengaduk.

Tabel 1. Komposisi bahan aktif Rootone F

\begin{tabular}{lc}
\hline Bahan aktif & $\begin{array}{c}\text { Persentase } \\
(\%)\end{array}$ \\
\hline 1-Napthalene Acetamida (NAA) & $0.067 \%$ \\
2-metil-1-Napthalene & $0.013 \%$ \\
Acetatamida (NAD) & \\
2-metil-1-naftalenasetat & $0.33 \%$ \\
Indol Butyric Acid (IBA) & $0.057 \%$ \\
Tiram & $4.00 \%$ \\
\hline
\end{tabular}

\section{Metode}

Penelitian

menggunakan
Rancangan Acak Kelompok (RAK) faktorial dengan faktor pertama yaitu aksesi mutan putatif (Varietas Ciinten) yang terdiri dari:

- $\mathrm{MP1}=$ mutan putatif 1 , dosis 25 Gy pada fase benih dengan radikula

- $\mathrm{MP2}=$ mutan putatif 2 , dosis 50 Gy pada fase benih

- $\mathrm{MP3}=$ mutan putatif 3 , dosis 50 Gy pada fase benih

- $\mathrm{MP4}=$ mutan putatif 4 , dosis 25 Gy pada fase benih

- Kontrol (Varietas Ciinten)

Faktor kedua adalah ZPT yang terdiri dari tujuh taraf:

- Air kelapa 25\% = $125 \mathrm{ml}$ air kelapa : $375 \mathrm{ml}$ air

- Air kelapa $50 \%=250 \mathrm{ml}$ air kelapa : $250 \mathrm{ml}$ air

- Air kelapa 75\% = $375 \mathrm{ml}$ air kelapa : $125 \mathrm{ml}$ air

- Rootone F 0.5 g

- Rootone F $1.0 \mathrm{~g}$

- Rootone F 1.5 g

- Kontrol (Air)

Masing-masing perlakuan diulang sebanyak 4 kali, sehingga terdapat 140 satuan percobaan. Tiap satu satuan percobaan terdiri dari 3 tanaman sehingga diperoleh total 420 tanaman.

\section{Analisis Data}

Analisa data menggunakan analisis ragam dengan aplikasi STAR (Statistical 
Tool for Agricultural Research) berdasarkan uji $\mathrm{F}$ taraf $\alpha 5 \%$. Uji BNT (Beda Nyata Terkecil) taraf $\alpha \quad 5 \%$ dilakukan pada data yang berpengaruh nyata.

\section{HASIL DAN PEMBAHASAN}

\section{Rekapitulasi Sidik Ragam}

Hasil analisis sidik ragam (ANOVA) pada pertumbuhan aksesi lada terhadap ZPT yang diberikan pada uji $\mathrm{F}$ disajikan pada Tabel 1. Penyungkupan dan perendaman dengan air kelapa tersaji pada Gambar 1.

Tabel 1. Rekapitulasi sidik ragam

\begin{tabular}{|c|c|c|c|c|}
\hline \multirow{2}{*}{ Peubah } & \multirow{2}{*}{ MST } & \multicolumn{3}{|c|}{ F-hitung } \\
\hline & & Aksesi & ZPT & Interaksi \\
\hline \multirow{4}{*}{$\begin{array}{l}\text { Persen- } \\
\text { tase hidup } \\
\quad(\mathrm{PH})\end{array}$} & 5 & tn & $* *$ & $* *$ \\
\hline & 6 & tn & $* *$ & $* *$ \\
\hline & 7 & tn & $*$ & $* *$ \\
\hline & 8 & th & tn & tn \\
\hline \multirow{4}{*}{$\begin{array}{l}\text { Jumlah } \\
\text { tunas (JT) }\end{array}$} & 5 & $* *$ & tn & tn \\
\hline & 6 & $* *$ & tn & tn \\
\hline & 7 & $* *$ & tn & tn \\
\hline & 8 & tn & tn & tn \\
\hline \multirow{2}{*}{$\begin{array}{c}\text { Tinggi } \\
\text { tunas (TT) }\end{array}$} & 7 & $* *$ & tn & tn \\
\hline & 8 & $* *$ & $\operatorname{tn}$ & $\operatorname{tn}$ \\
\hline \multirow{4}{*}{$\begin{array}{c}\text { Jumlah } \\
\text { daun (JD) }\end{array}$} & 5 & $* *$ & tn & tn \\
\hline & 6 & tn & tn & tn \\
\hline & 7 & $* *$ & $*$ & tn \\
\hline & 8 & $* *$ & tn & tn \\
\hline \multirow{2}{*}{$\begin{array}{c}\text { Panjang } \\
\text { daun (PD) }\end{array}$} & 7 & ** & tn & tn \\
\hline & 8 & $* *$ & $\operatorname{tn}$ & th \\
\hline \multirow{2}{*}{$\begin{array}{c}\text { Lebar } \\
\text { daun (LD) }\end{array}$} & 7 & $* *$ & $* *$ & tn \\
\hline & 8 & $* *$ & tn & tn \\
\hline \multicolumn{5}{|c|}{$\begin{aligned} \text { Keterangan: } & =\text { berpengaruh nyata, } \\
& { }^{* *}= \\
& \text { berpengaruh sangat nyata, tn: } \\
& 5 \%\end{aligned}$} \\
\hline
\end{tabular}

Berdasarkan hasil analisis sidik ragam (ANOVA) diketahui bahwa aksesi berpengaruh sangat nyata pada peubah jumlah tunas umur 5 -7 MST, tinggi tunas umur 7 dan 8 MST, jumlah daun umur 5, 7 dan 8 MST, panjang daun umur 7 dan 8 MST dan lebar daun umur 7 dan 8 MST. Perlakuan ZPT juga berpengaruh nyata pada peubah persentase hidup umur $5-7$ MST, jumlah daun dan lebar daun umur 7 MST. Interaksi antara aksesi dan ZPT tampak pada peubah persentase hidup pada umur 5, 6 dan 7 MST.

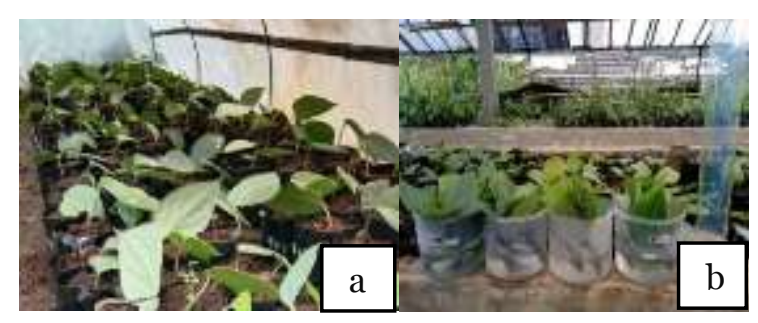

Gambar 1. a. Setek lada yang disungkup selama tiga minggu dan b. cara perendaman dengan air kelapa

\section{Persentase Hidup (\%)}

Interaksi jenis aksesi dengan jenis ZPT tidak berbeda nyata pada semua kombinasi perlakuan, kecuali pada aksesi MP1 dengan perlakuan Rootone F 1.5 gr umur 5-7 MST. Kombinasi perlakuan Rootone-F 1.5 g aksesi MP1 memiliki persentase hidup paling rendah dibandingkan perlakuan lainnya yaitu sebesar 50\% pada umur 5, 6 dan 7 minggu setelah tanam. Hal ini diduga pemberian Rootone F 1.5 g terlalu tinggi sehingga dapat merusak tanaman, menghambat pertumbuhan dan perkembangan tunas, menyebabkan penguningan sehingga daun gugur, batang menjadi hitam dan menyebabkan 
kematian. Sama halnya dalam penelitian Ardana (2009) penggunaan ZPT dalam jumlah yang tepat akan berpengaruh pada pertumbuhan yang baik. Menurut
Nengsih et al., (2016), kandungan auksin dan sitokinin yang seimbang akan meningkatkan persentase hidup setek pada setek yang berasal dari sulur panjat.

Tabel 2. Interaksi perlakuan ZPT dan aksesi terhadap peubah persentase hidup pada 5-7 MST

\begin{tabular}{|c|c|c|c|c|c|}
\hline ZPT & Ciinten & MP1 & MP2 & MP3 & MP4 \\
\hline \multicolumn{6}{|c|}{5 MST } \\
\hline Air kelapa 25\% & $91.7 \mathrm{a}$ & $100 \mathrm{a}$ & $91.7 \mathrm{a}$ & $83.4 \mathrm{a}$ & $100 \mathrm{a}$ \\
\hline Air kelapa 50\% & $91.7 \mathrm{a}$ & $100 \mathrm{a}$ & $75.0 \mathrm{a}$ & $100 \mathrm{a}$ & $100 \mathrm{a}$ \\
\hline Air kelapa 75\% & $100 \mathrm{a}$ & $91.7 \mathrm{a}$ & $91.7 \mathrm{a}$ & $75.0 \mathrm{a}$ & $75.0 \mathrm{a}$ \\
\hline Rootone F 0.5 g & $100 \mathrm{a}$ & $100 \mathrm{a}$ & $100 \mathrm{a}$ & $100 \mathrm{a}$ & $83.3 \mathrm{a}$ \\
\hline Rootone F $1 \mathrm{~g}$ & $91.7 \mathrm{a}$ & $75.0 \mathrm{ab}$ & $75.0 \mathrm{a}$ & $83.3 \mathrm{a}$ & $100 \mathrm{a}$ \\
\hline Rootone F $1.5 \mathrm{~g}$ & $100 \mathrm{a}$ & $50.0 \mathrm{~b}$ & $100 \mathrm{a}$ & $100 \mathrm{a}$ & $83.4 \mathrm{a}$ \\
\hline Kontrol & $100 \mathrm{a}$ & $100 \mathrm{a}$ & $100 \mathrm{a}$ & $100 \mathrm{a}$ & $100 \mathrm{a}$ \\
\hline \multicolumn{6}{|c|}{$6 \mathrm{MST}$} \\
\hline Air kelapa 25\% & $91.7 \mathrm{a}$ & $100 \mathrm{a}$ & $91.7 \mathrm{a}$ & $83.4 \mathrm{a}$ & $91.7 \mathrm{a}$ \\
\hline Air kelapa 50\% & $91.7 \mathrm{a}$ & $100 \mathrm{a}$ & $75.0 \mathrm{a}$ & $100 \mathrm{a}$ & $91.7 \mathrm{a}$ \\
\hline Air kelapa 75\% & $91.7 \mathrm{a}$ & $91.7 \mathrm{a}$ & $83.3 \mathrm{a}$ & $75.0 \mathrm{a}$ & $75.0 \mathrm{a}$ \\
\hline Rootone F $0.5 \mathrm{~g}$ & $100 \mathrm{a}$ & $100 \mathrm{a}$ & $100 \mathrm{a}$ & $100 \mathrm{a}$ & $83.3 \mathrm{a}$ \\
\hline Rootone F $1 \mathrm{~g}$ & $91.7 \mathrm{a}$ & $75.0 \mathrm{ab}$ & $83.4 \mathrm{a}$ & $83.3 \mathrm{a}$ & $100 \mathrm{a}$ \\
\hline Rootone F $1.5 \mathrm{~g}$ & $100 \mathrm{a}$ & $50.0 \mathrm{~b}$ & $100 \mathrm{a}$ & $100 \mathrm{a}$ & $83.4 \mathrm{a}$ \\
\hline Kontrol & $100 \mathrm{a}$ & $100 \mathrm{a}$ & $100 \mathrm{a}$ & $100 \mathrm{a}$ & $100 \mathrm{a}$ \\
\hline \multicolumn{6}{|c|}{$7 \mathrm{MST}$} \\
\hline Air kelapa 25\% & $91.7 \mathrm{a}$ & $91.7 \mathrm{a}$ & $91.7 \mathrm{a}$ & $83.4 \mathrm{a}$ & $91.7 \mathrm{a}$ \\
\hline Air kelapa 50\% & $91.7 \mathrm{a}$ & $100 \mathrm{a}$ & $75.0 \mathrm{a}$ & $100 \mathrm{a}$ & $91.7 \mathrm{a}$ \\
\hline Air kelapa 75\% & $91.7 \mathrm{a}$ & $100 \mathrm{a}$ & $83.3 \mathrm{a}$ & $75.0 \mathrm{a}$ & $75.0 \mathrm{a}$ \\
\hline Rootone F $0.5 \mathrm{~g}$ & $100 \mathrm{a}$ & $100 \mathrm{a}$ & $91.7 \mathrm{a}$ & $100 \mathrm{a}$ & $83.3 \mathrm{a}$ \\
\hline Rootone F $1 \mathrm{~g}$ & $83.4 \mathrm{a}$ & $75.0 \mathrm{ab}$ & $75.0 \mathrm{a}$ & $75.0 \mathrm{a}$ & $100 \mathrm{a}$ \\
\hline Rootone F $1.5 \mathrm{~g}$ & $91.7 \mathrm{a}$ & $50.0 \mathrm{~b}$ & $100 \mathrm{a}$ & $100 \mathrm{a}$ & $83.4 \mathrm{a}$ \\
\hline Kontrol & $100 \mathrm{a}$ & $91.7 \mathrm{a}$ & $91.7 \mathrm{a}$ & $100 \mathrm{a}$ & $100 \mathrm{a}$ \\
\hline
\end{tabular}

Keterangan: angka yang diikuti huruf yang sama pada kolom yang sama tidak berbeda nyata berdasarkan uji BNT taraf $\alpha 5 \%$

\section{Jumlah Tunas}

Perlakuan aksesi lada

menunjukkan adanya perbedaan respon peubah jumlah tunas pada umur 5, 6, 7 MST. Aksesi MP2 (50 Gy, fase benih), MP1 (25 Gy, fase benih dengan radikula), dan Ciinten memiliki rata-rata jumlah tunas lebih banyak dibandingkan dengan aksesi MP3 (50 Gy, fase benih) dan MP4 (25 Gy, fase benih) pada 5 MST (Tabel 3). Hal ini dikarenakan MP3 dan MP4 mengalami pertumbuhan tunas lebih lama daripada aksesi lainnya.

Tabel 3. Respons aksesi lada hasil iradiasi sinar gamma terhadap peubah jumlah tunas pada 5-7 MST

\begin{tabular}{llll}
\hline Aksesi & $5 \mathrm{MST}$ & $6 \mathrm{MST}$ & $7 \mathrm{MST}$ \\
\hline MP1 & $0.37 \mathrm{ab}$ & $0.51 \mathrm{ab}$ & $0.58 \mathrm{~b}$ \\
MP2 & $0.43 \mathrm{a}$ & $0.63 \mathrm{a}$ & $0.72 \mathrm{ab}$ \\
MP3 & $0.29 \mathrm{~b}$ & $0.45 \mathrm{~b}$ & $0.73 \mathrm{a}$ \\
MP4 & $0.00 \mathrm{c}$ & $0.09 \mathrm{c}$ & $0.65 \mathrm{ab}$ \\
Ciinten & $0.32 \mathrm{ab}$ & $0.41 \mathrm{~b}$ & $0.37 \mathrm{c}$ \\
\hline
\end{tabular}

Keterangan: angka yang diikuti huruf yang sama pada kolom yang sama tidak berbeda nyata berdasarkan uji BNT taraf $\alpha$ 5\%

Varietas Ciinten mengalami penghambatan munculnya jumlah tunas setiap minggunya dibandingkan dengan 
aksesi yang berasal dari mutan putatif. Sementara MP4 mengalami pertumbuhan tunas lebih lambat pada umur 5-6 MST dibandingkan perlakuan aksesi lainnya. Aksesi MP2, MP3, dan MP4 menunjukkan pertumbuhan tunas lebih baik jika dibandingkan varietas asal Ciinten.

\section{Tinggi Tunas (cm)}

Pertumbuhan mutan putatif lada pada peubah tinggi tunas umur 7 dan 8 MST memperlihatkan perbedaan yang nyata jika dibandingkan dengan varietas Ciinten (Tabel 4).

Tabel 4. Respons aksesi lada hasil iradiasi sinar gamma terhadap peubah tinggi tunas pada 5-7 MST

\begin{tabular}{lll}
\hline Aksesi & $7 \mathrm{MST}$ & $8 \mathrm{MST}$ \\
\hline MP1 & $3.16 \mathrm{a}$ & $4.18 \mathrm{a}$ \\
MP2 & $3.50 \mathrm{a}$ & $4.36 \mathrm{a}$ \\
MP3 & $3.10 \mathrm{a}$ & $4.81 \mathrm{a}$ \\
MP4 & $3.31 \mathrm{a}$ & $5.00 \mathrm{a}$ \\
Ciinten & $1.34 \mathrm{~b}$ & $2.21 \mathrm{~b}$ \\
\hline
\end{tabular}

Keterangan: angka yang diikuti huruf yang sama pada kolom yang sama tidak berbeda nyata berdasarkan uji BNT taraf $\alpha$ 5\%

Mutan putatif pada keturunan M1V4 (mutan 1, varian 4) hasil iradiasi memiliki tunas yang lebih tinggi dibandingkan dengan varietas pembanding Ciinten, sedangkan pada keturunan M1 pada penelitian Meilawati et al. (2016), perlakuan iradiasi sinar gamma dapat mempengaruhi pertumbuhan tinggi tanaman, panjang daun dan jumlah tunas yang lebih sedikit dibandingkan dengan Varietas Ciinten.

\section{Jumlah Daun (helai)}

Daun merupakan organ terpenting tumbuhan karena memiliki fungsi utama sebagai tempat fotosintesis (Wahyuningtyas et al., 2017). Berdasarkan Tabel 5, perlakuan MP2 memiliki jumlah daun lebih banyak dibandingkan dengan aksesi lainnya yaitu sebesar 0.33 helai tetapi tidak berbeda nyata dengan perlakuan MP1 dan Ciinten pada umur 5 MST. Pada umur 7 MST, aksesi MP3 memiliki jumlah daun yang lebih banyak dibandingkan dengan aksesi lainnya yaitu 1 helai namun tidak berbeda nyata dengan perlakuan MP4. Sedangkan pada umur 8 MST, aksesi MP3 memiliki jumlah daun lebih banyak dibandingkan aksesi lain yaitu 1.4 helai.

Tabel 5. Respons aksesi lada hasil iradiasi sinar gamma terhadap peubah jumlah daun pada 5-8 MST

\begin{tabular}{llll}
\hline Aksesi & $5 \mathrm{MST}$ & $7 \mathrm{MST}$ & $8 \mathrm{MST}$ \\
\hline MP1 & $0.26 \mathrm{ab}$ & $0.75 \mathrm{~b}$ & $1.12 \mathrm{~b}$ \\
MP2 & $0.33 \mathrm{a}$ & $0.81 \mathrm{~b}$ & $1.14 \mathrm{~b}$ \\
MP3 & $0.18 \mathrm{~b}$ & $1.0 \mathrm{a}$ & $1.48 \mathrm{a}$ \\
MP4 & $0.02 \mathrm{c}$ & $0.8 \mathrm{ab}$ & $1.13 \mathrm{~b}$ \\
Ciinten & $0.19 \mathrm{ab}$ & $0.30 \mathrm{c}$ & $0.40 \mathrm{c}$ \\
\hline
\end{tabular}

Keterangan: angka yang diikuti huruf yang sama pada kolom yang sama tidak berbeda nyata berdasarkan uji BNT taraf $\alpha 5 \%$

Pada umur 7 MST dan 8 MST jumlah daun Ciinten lebih sedikit dibandingkan aksesi lain pada 7 dan 8 MST. Hal ini disebabkan varietas Ciinten merupakan varietas asal yang memiliki sifat moderat tahan terhadap penyakit busuk pangkal batang. Diberikannya irradiasi sinar gamma pada aksesi lada 
bertujuan untuk meningkatkan ketahanan terhadap penyakit busuk pangkal batang, sehingga jumlah daun hasil irradiasi sinar gamma lebih banyak jika dibandingkan dengan varietas asalnya (Ciinten). Sejalan dengan penelitian Meilawati et al. (2016) bahwa hasil iradiasi sinar gamma dapat mempengaruhi ketahanan daun tanaman lada terhadap infeksi $P$. capsici. Sebanyak delapan belas mutan putatif tahan terhadap infeksi $P$. capsici penyebab busuk pangkal batang.

Tabel 6. Nilai tengah pengaruh perlakuan ZPT terhadap peubah jumlah daun (helai) pada 7 MST

\begin{tabular}{lc}
\hline ZPT & $7 \mathrm{MST}$ \\
\hline Air kelapa 25\% & $3.58 \mathrm{ab}$ \\
Air kelapa 50\% & $4.34 \mathrm{a}$ \\
Air kelapa 75\% & $2.67 \mathrm{c}$ \\
Rootone F 0.5 g & $4.50 \mathrm{a}$ \\
Rootone F 1 g & $4.76 \mathrm{a}$ \\
Rootone F 1.5 g & $3.08 \mathrm{bc}$ \\
Kontrol & $3.50 \mathrm{ab}$ \\
\hline Keterangan: angka yang diikuti huruf yang sama \\
pada kolom yang sama tidak berbeda \\
nyata berdasarkan uji BNT taraf $\alpha 5 \%$
\end{tabular}

Berdasarkan hasil penelitian, perlakuan ZPT yang diuji pada peubah jumlah daun menunjukkan hasil yang berbeda nyata (Tabel 6). Pemberian ZPT Rootone-F 1 g memiliki jumlah daun lebih banyak jika dibandingkan dengan perlakuan air kelapa 75\% dan Rootone-F 1.5 g. Menurut Ramadan et al. (2016), proses metabolisme dalam tanaman dapat dipengaruhi oleh faktor tanaman seperti bahan setek ataupun faktor luar tanaman seperti ZPT, suhu, intensitas cahaya, ataupun kelembaban yang optimal.

\section{Panjang dan Lebar Daun (cm)}

Hasil penelitian menunjukkan adanya perbedaan yang nyata tiap aksesi terhadap peubah panjang daun dan lebar daun umur 7 dan 8 MST ( Tabel 7).

Tabel 7. Respons aksesi lada hasil iradiasi sinar gamma terhadap peubah panjang dan lebar daun pada 7 dan 8 MST

\begin{tabular}{lcccc}
\hline \multirow{2}{*}{ Aksesi } & \multicolumn{2}{c}{ Panjang Daun $(\mathrm{cm})$} & \multicolumn{2}{c}{ Lebar daun $(\mathrm{cm})$} \\
\cline { 2 - 5 } & $7 \mathrm{MST}$ & $8 \mathrm{MST}$ & $7 \mathrm{MST}$ & $8 \mathrm{MST}$ \\
\hline MP1 & $2.89 \mathrm{~b}$ & $4.29 \mathrm{~b}$ & $0.67 \mathrm{c}$ & $0.88 \mathrm{c}$ \\
MP2 & $4.13 \mathrm{a}$ & $5.18 \mathrm{ab}$ & $2.00 \mathrm{ab}$ & $2.46 \mathrm{~b}$ \\
MP3 & $4.40 \mathrm{a}$ & $5.69 \mathrm{a}$ & $2.12 \mathrm{ab}$ & $2.82 \mathrm{ab}$ \\
MP4 & $2.84 \mathrm{~b}$ & $4.10 \mathrm{~b}$ & $2.37 \mathrm{a}$ & $3.25 \mathrm{a}$ \\
Ciinten & $0.15 \mathrm{c}$ & $1.51 \mathrm{c}$ & $1.63 \mathrm{~b}$ & $2.48 \mathrm{~b}$ \\
\hline
\end{tabular}

Keterangan: angka yang diikuti huruf yang sama pada kolom yang sama tidak berbeda nyata berdasarkan uji BNT taraf $\alpha 5 \%$

Peubah jenis aksesi menunjukkan bahwa aksesi MP3 dan MP2 memiliki daun terpanjang berturut-turut sekitar $4.40 \mathrm{~cm}$ dan $4.13 \mathrm{~cm}$ dibandingkan dengan aksesi lainnya pada umur 7 MST. Saat umur 8 MST, aksesi MP3 memiliki daun terpanjang dibandingkan dengan aksesi lainnya yaitu sebesar $5.69 \mathrm{~cm}$ tetapi tidak berbeda nyata dengan perlakuan MP2 yaitu sebesar $5.18 \mathrm{~cm}$ dibandingkan dengan Varietas Ciinten. Menurut Meilawati et al. (2016) iradiasi berpengaruh terhadap variasi bentuk daun, warna daun, kerapatan stomata, indeks stomata dan ketahanan daun terhadap infeksi P. capsici.

Berdasarkan Tabel 7, jenis aksesi yang diuji menunjukkan bahwa 
perlakuan MP4 memiliki daun terlebar dibandingkan dengan aksesi lainnya yaitu sebesar $2.37 \mathrm{~cm}$ tetapi tidak berbeda nyata dengan perlakuan MP2 dan MP3 pada umur 7 MST. Pada umur 8 MST, perlakuan MP4 juga masih memiliki daun terlebar dibandingkan dengan varietas Ciinten, MP1 dan MP2 yaitu sebesar $3.25 \mathrm{~cm}$ tetapi tidak berbeda nyata dengan perlakuan MP3.

Tabel 8. Nilai tengah pengaruh perlakuan ZPT terhadap peubah lebar daun (cm) pada 7 MST

\begin{tabular}{ll}
\hline ZPT & 7 MST \\
\hline Air kelapa 25\% & $1.67 \mathrm{ab}$ \\
Air kelapa 50\% & $1.68 \mathrm{ab}$ \\
Air kelapa 75\% & $1.23 \mathrm{~b}$ \\
Rootone F 0.5 g & $2.35 \mathrm{a}$ \\
Rootone F 1 g & $2.02 \mathrm{ab}$ \\
Rootone F 1.5 g & $1.53 \mathrm{ab}$ \\
Kontrol & $1.82 \mathrm{ab}$ \\
\hline
\end{tabular}

Keterangan: angka yang diikuti huruf yang sama pada kolom yang sama tidak berbeda nyata berdasarkan uji BNT taraf $\alpha 5 \%$

Berdasarkan Tabel 8, ZPT yang diuji menunjukkan bahwa perlakuan Rootone F $0.5 \mathrm{~g}$ memiliki nilai tengah peubah daun lebih lebar dibandingkan dengan perlakuan air kelapa 75\%. Penggunaan Rootone- $F$ pada setekan menunjukkan hasil yang lebih baik karena kandungan di dalam Rootone $\mathrm{F}$ yang terdiri dari IBA, IAA dan NAA (Tabel 1) yang merupakan hormon jenis auksin ketika diberikan pada konsentrasi optimal akan mempercepat terjadinya proses fisiologis tanaman.

Berdasarkan penelitian yang dilakukan oleh Gustini et al. (2012) pemberian Rootone $\mathrm{F}$ yang dioles pada varietas salak mampu meningkatkan pembentukan akar, tinggi tanaman dan luas daun, dengan konsentrasi optimal 150 mg/anakan. Dari hasil penelitian ini pemberian Rootone $\mathrm{F}$ yang dioles pada konsentrasi $0.5 \mathrm{~g}$ memberikan hasil optimum untuk peubah lebar daun. Hal ini menunjukkan tanaman lada mampu menyerap auksin yang terkandung pada Rootone F optimalnya pada konsentrasi 0.5 g. Semakin tinggi konsentrasi yang digunakan akan mengakibatkan toksisitas. Pengaruh Rootone F yang nyata terhadap peubah lebar daun lada disebabkan oleh transport auksin yang terkandung dalam Rootone $\mathrm{F}$ terjadi dari akar ke pucuk.

\section{SIMPULAN}

1. Respons pada aksesi MP3 dan MP4 memiliki jumlah tunas, tinggi tunas, jumlah daun, panjang daun, dan lebar daun lebih baik daripada varietas Ciinten.

2. Respons perlakuan ZPT Rootone F 0.5 g memiliki daun lebih lebar dan jumlah daun lebih banyak dibandingkan dengan air kelapa 75\%, namun tidak berbeda nyata dengan kontrol pada umur 7 MST.

3. Terdapat interaksi ZPT dan aksesi yang diuji. Seluruh interaksi memiliki persentase hidup $>75 \%$ kecuali 
perlakuan Rootone F $1.5 \mathrm{~g}$ aksesi MP1

memiliki persentase hidup nyata lebih rendah dibandingkan perlakuan lainnya.

\section{UCAPAN TERIMAKASIH}

Ucapan terimakasih disampaikan kepada Balai Penelitian Tanaman Rempah dan Obat (BALITTRO) Bogor, Tim peneliti Lada serta Ramdhan Arismaya, Suryatna, Totong Sugandi dan seluruh teknisi yang ada di Rumah Kaca Plasma Nutfah Pemuliaan Tanaman yang telah membantu pelaksanaan penelitian.

\section{DAFTAR PUSTAKA}

Ardana, R.C. (2009). Pengaruh macam zat pengatur tumbuh dan frekuensi penyemprotan terhadap pertumbuhan awal bibit gelombang cinta (Anthurium plowmanii). Skripsi. UNS Surakarta.

Budianto, E. A., Badami, K., \& Arsyadmunir, A. (2013). Pengaruh kombinasi macam ZPT dengan lama perendaman yang berbeda terhadap keberhasilan pembibitan sirih merah (Piper crocatum R.) secara setek. Jurnal Agroekoteknologi Fakultas Pertanian. Universitas Trunojoyo Madura 6(2), 103-111.

Darlina, Hasanuddin, \& Rahmatan, H. (2016). Pengaruh penyiraman air kelapa (Cocos nucifera L.) terhadap pertumbuhan vegetatif lada (Piper nigrum L.). Jurnal Ilmiah Mahasiswa Pendidikan Biologi 3(1), 20-28.

Gustini, D., Fatonah, S., \& Sujarwati.
(2012). Pengaruh Rootone F dan pupuk bayfolan tehadap pembentukan akar dan pertumbuhan anakan salak pondoh (Salacca edulis R). Jurnal Biospecies 5(1), 8-13.

Meilawati, N. L. W., Bermawie, N., Purwito, A. \& Manohara, D. (2016). Respon tanaman lada (Piper nigrum L.) Varietas Ciinten terhadap iradiasi sinar gamma. Jurnal Littri 22(2), 71-80.

Nengsih, Y., Marpaung, R., \& Alkori. (2016). Sulur panjat merupakan sumber setek terbaik untuk perbanyakan bibit lada secara vegetatif. Jurnal Media Pertanian 1(1), 29-35.

Ramadan, V. R., Kendarini, N., \& Ashari, S. (2016). Kajian pemberian zat pengatur tumbuh terhadap pertumbuhan stek tanaman buah naga (Hylocereus costaricensis). Jurnal Produksi Tanaman 4(3), 180-186.

Zuhroh, M. U., Hartati, A., \& Efendy, M. C. (2019). Respon konsentrasi Rootone-F dan GA-3 terhadap pertumbuhan setek tiga ruas sulur buah pada pembibitan lada perdu (Piper nigrum L.) varietas belatung. Agrotechbiz Jurnal Ilmiah Pertanian 6(2), 38-47. 